BULLETIN Bulletin hispanique

HISPANIQUE Université Michel de Montaigne Bordeaux

113-1 | 2011

Actes de 2 colloques

\title{
Bibliotecas, imprentas y difusión de noticias en el Perú colonial
}

Teodoro Hampe Martínez

\section{(2) OpenEdition}

Journals

\section{Edición electrónica}

URL: http://journals.openedition.org/bulletinhispanique/1547

DOI: 10.4000/bulletinhispanique. 1547

ISSN: 1775-3821

\section{Editor}

Presses universitaires de Bordeaux

\section{Edición impresa}

Fecha de publicación: 1 junio 2011

Paginación: 409-432

ISBN: 978-2-86781-740-3

ISSN: 0007-4640

\section{Referencia electrónica}

Teodoro Hampe Martínez, « Bibliotecas, imprentas y difusión de noticias en el Perú colonial », Bulletin hispanique [En línea], 113-1 | 2011, Publicado el 01 junio 2014, consultado el 19 abril 2019. URL : http:// journals.openedition.org/bulletinhispanique/1547 ; DOI : 10.4000/bulletinhispanique.1547 


\title{
Bibliotecas, imprentas y difusión de noticias en el Perú colonial
}

\author{
Teodoro Hampe Martínez \\ Universidad de Lima - Perú
}

Large synthèse historiographique de la recherche sur l'imprimé dans le Nouveau Monde qui comprend l'histoire de l'imprimerie, des bibliothèques, des lectures et de la presse, des travaux pionniers de José Toribio Medina aux plus récents. L'étude signale également tout ce qui reste à explorer en ce qui concerne l'impact qu'exercent les bibliothèques, le commerce du livre et les ateliers d'imprimerie sur la vie sociale et culturelle du Pérou colonial et elle indique, étant donné le rôle limité de la culture imprimée à cette époque, les nouvelles pistes suivies pour parvenir à une meilleure vision de ce phénomène.

Amplia sintesis historiográfica de la investigación sobre el impreso en el Nuevo Mundo que abarca la historia de la imprenta, de las bibliotecas, de las lecturas y de la prensa, desde los trabajos pioneros de José Toribio Medina hasta los más recientes. También señala lo mucho que queda por explorar respecto al impacto que ejercieron las bibliotecas, el comercio de libros y los talleres de imprenta sobre la vida social y cultural del Perú colonial, e indica, dado el rol restringido de la cultura impresa en este periodo, las nuevas pistas seguidas para conseguir una mejor visión del dicho fenómeno.

A large historiographic syntesis is presented on the research about printed matter in the New World, composed of the history of printing, libraries, reading and press, from José Toribio Médina to the most recent Works. It also points out all that is yet to be explored in the field of the impact that libraries, books trade and printing workshops on the social and cultural life in colonial Peri. It indicates, given the limited role of printed culture at that time, new pathes to come to a better understanding of the phenomenon.

Mots-clés : Histoire du livre - Bibliothèques - Imprimés - Société coloniale - Pérou.

Bulletin Hispanique, Tome 113, nº 1 - juin 2011 - p. 409 à 432 
$\mathrm{D}$ E LOS ańos 1950 en adelante, la historia del libro se ha convertido en una disciplina de creciente interés y estimulantes discusiones en América hispana. Por cuanto se refiere particularmente al período de la conquista y colonización, una serie de importantes contribuciones (empezando por la clásica obra de Irving A. Leonard, Los libros del conquistador, trad. 1953) han renovado nuestra visión sobre el rol y el impacto de los materiales impresos en las sociedades del Nuevo Mundo. Estas contribuciones, producidas por historiadores, filólogos, filósofos y otros investigadores de las humanidades y las ciencias sociales, han probado la notable significación del trabajo interdisciplinario. En virtud de esta condición, se han puesto en escena nuevos hechos históricos y fuentes originales, al mismo tiempo que se ha producido un cambio cualitativo en la historia intelectual y cultural. Más aun, la influencia francesa de la historia de las mentalidades (notable especialmente desde el final de los años 1970) ha servido para vincular la evolución de las bibliotecas, imprentas y comercio de libros con un amplio espectro de actitudes, ideologías y prácticas de la vida cotidiana.

\section{FUNDAMENTOS DE LA INVESTIGACIÓN HISTÓRICA}

Con algunas notables excepciones, sin embargo, la investigación sobre el impacto social de la imprenta o las tendencias evolutivas de la cultura impresa en el Nuevo Mundo no ha concitado un interés general. La literatura se ha centrado ante todo en documentar la exportación de libros de Europa hacia América y en determinar el rol de los materiales impresos en la diseminación de las ideas europeas. La mayor parte de la investigación sobre libros en la época colonial concierne particularmente a México y Lima en los siglos XVI y XVII, por ser las dos ciudades con las mayores tradiciones tipográficas. Como epicentros de la cultura y política del Imperio español en América hasta la era de las reformas borbónicas, México y Lima fueron también los mayores puntos de distribución para los libros importados de Europa. En cambio, relativamente pocos estudios han enfocado la historia social de la imprenta en el siglo XVIII y las primeras décadas del siglo XIX, en vísperas de la independencia de América hispana.

Las primeras prensas fueron traídas a Ciudad de México y Lima, por tipógrafos oriundos del norte de Italia (Giovanni Paolo de Brescia y Antonio Ricardo de Turín), con el explícito propósito de ayudar a los misioneros en la 
cristianización de las poblaciones nativas. Catecismos multilingües, folletos de instrucción religiosa, gramáticas y vocabularios de idiomas amerindios fueron los principales productos de las imprentas a principios de la época colonial. Mientras el siglo XVI hacía su paso, la preocupación inicial de la Corona por la moral y el bienestar espiritual de los tributarios amerindios cambió hacia la educación o el entretenimiento de un creciente número de colonos de origen europeo en las capitales y mayores ciudades virreinales. Para mediados del siglo XVII, la imprenta colonial atendía sobre todo los propósitos de los administradores peninsulares y reflejaba la prosperidad creciente y las necesidades intelectuales de los colonos europeos, criollos o mestizos. En Nueva España, por ejemplo, de 1539 hasta 1600 alrededor de un tercio (31,33 por ciento) de los impresos locales fueron en idiomas nativos indígenas, mientras que en la centuria siguiente los trabajos publicados en estos idiomas disminuyeron significativamente, contabilizando solo el 3 por ciento del total producido ${ }^{1}$.

Asíes que, mediantela colaboración de sacerdotes cristianos con escribientes indígenas, una colección de textos nativos fue producida durante todo ese período por personajes amerindios alfabetizados, quienes transcribieron textos «tradicionales» en latín, castellano o su idioma nativo, o bien compusieron nuevos textos por comisión de las autoridades españolas. Como es bastante sabido, la colección de manuscritos mesoamericanos pintados previa y posteriormente a la Conquista se conoce bajo el nombre de códices. Sobre la base del trabajo realizado a finales del siglo XIX y principios del siglo XX por anticuarios, antropólogos e historiadores del arte, la literatura académica reciente ha reexaminado los textos de origen nativo y las variadas formas de registro o conservación de la memoria colectiva, ya sea en folios pintados o en cuerdas anudadas, como los quipus del mundo andino ${ }^{2}$.

Haciendo un inventario de la producción limitada de las imprentas en las colonias y poniendo de relieve documentos legislativos relacionados con el control metropolitano sobre los libros y la lectura, una serie de bibliógrafos americanistas de la segunda mitad del siglo XIX parecieron dar

1. M. Chocano Mena, «Colonial printing and metropolitan books: printed texts and the shaping of scholarly culture in New Spain, 1539-1700», Colonial Latin American Historical Review (Albuquerque, NM), vol. 6, 1997, p. 73. Esta autora menciona una serie de factores que contribuyeron a dicho fenómeno, incluyendo la caída demográfica de las comunidades nativas y el fracaso de algunos proyectos misioneros, pero sugiere también el desarrollo de una intelligentsia local como causa importante para la creciente "hispanización" de la imprenta (p. 76).

2. C. Radicati di Primeglio, Estudios sobre los quipus; compilación y estudio introductorio de Gary Urton, Lima, 2006. 
sólidas pruebas documentales a la opinión de que las instituciones españolas sirvieron como mecanismos represivos que habían contenido o estrechado la vida intelectual en las colonias.

Los múltiples trabajos del erudito chileno José Toribio Medina (18521930), una figura sobresaliente de la bibliografía hispanoamericana, desempeñaron un papel clave en la consolidación de esa visión oscurantista sobre el pasado cultural de la región. Emprendida sobre la base de bibliografías regionales, la monumental obra de Medina titulada Biblioteca hispanoamericana (1493-1810), publicada en siete volúmenes de 1898 a 1907, junto con otros numerosos estudios suyos sobre la producción literaria colonial, el Santo Oficio de la Inquisición y algunos temas conexos, construyeron los fundamentos de estudios críticos modernos acerca de la historia del libro en nuestra región. Medina puso al descubierto una abundante legislación que restringía la exportación de libros al Nuevo Mundo, dando así más crédito a las opiniones reinantes sobre las instituciones españolas como mecanismos de represión que habían atrofiado la vida intelectual en las colonias.

\section{LAS BIBLIOTECAS PRIVADAS Y EL COMERCIO DE LIBROS EN EL MUNDO COLONIAL}

Como es bien sabido, cualquier biblioteca revela en gran extensión el espíritu de su dueño; pero esta característica adquiere un significado aun más grande en el contexto de comienzos de la Edad Moderna, cuando la rareza de los libros y sus elevados precios representaban inconvenientes mayores para la formación de una biblioteca ${ }^{3}$. En el período colonial de América la posesión de bibliotecas privadas fue ciertamente un privilegio de clase. El coleccionismo de libros era una actividad accesible solo para miembros del clero, nobles, profesionales (burócratas, maestros, abogados, médicos), algunos mercaderes y aun jefes indígenas ${ }^{4}$. A pesar de esto, sería equivocado considerar la divulgación de libros e ideas procedentes de Europa como un fenómeno puramente elitista, porque las creaciones literarias y doctrinas fundamentales de los más celebrados autores circularon también entre la gente de clase baja y los iletrados. Españoles y criollos pobres, mestizos e inclusive indios fueron instruidos mediante proverbios, cuentos populares,

3. Cf. P. Guibovich Pérez, "Las lecturas de Francisco de Isásaga», Histórica (Lima), vol. 10, 1986, p. 191.

4. C. A. González Sánchez, «Los libros de los españoles en el virreinato del Perú (siglos XVI y XVII)», Revista de Indias (Madrid), vol. 56, 1996, p. 16-22. 
baladas, canciones y tertulias, reuniones donde algún pasaje novelesco o un comentario moral eran leídos en alta voz.

Haciendo una comparación con las colecciones de libros conocidas para Nueva Espańa en la primera mitad del siglo XVI, se demuestran los logros bibliográficos relativamente modestos de los coleccionistas peruanos. Nada se asemeja en América del Sur a la biblioteca de cuatrocientos volúmenes reunida, con apoyo financiero oficial, por el obispo fray Juan de Zumárraga en la ciudad de México. Asimismo, nada se compara con el transporte de libros hecho en 1535 por el primer virrey mexicano, don Antonio de Mendoza, o con la biblioteca académica fundada el año siguiente en el Colegio de la Santa Cruz de Tlatelolco5.

Las colecciones privadas de libros proliferaron en el virreinato del Perú durante el siglo XVII, una época de verdadero apogeo en la economía de este territorio, cuando la sociedad criolla se establecía firmemente y su capital, Lima, engrandecía con residentes de buena formación cultural, deseosos de mantener contacto con las últimas actualidades espirituales e intelectuales de Europa. El pico más alto de esta dedicación académica parece haber sido alcanzado por el doctor Francisco de Ávila, un clérigo mestizo de origen cuzqueño. La biblioteca privada de este famoso «extirpador de idolatrías» de la provincia de Huarochirí y canónigo de la catedral de Lima, inventariada después de su muerte en 1647, llegó a constar de 3.108 volúmenes, incluyendo 45 manuscritos. De acuerdo con la evidencia reunida hasta ahora, esta debería ser considerada la más grande colección privada de libros en toda América a mediados del siglo XVII ${ }^{6}$.

No existen estadísticas precisas para describir el contenido proporcional de las bibliotecas privadas en el mundo colonial. Sin embargo, Irving A. Leonard -basando sus observaciones en evidencias tomadas principalmente de los registros de embarque- estimó que un 70 por ciento (o más) de los libros que circulaban en los siglos XVI y XVII en el Nuevo Mundo tenían que ver con asuntos religiosos ${ }^{7}$. Tratados sobre moralidad, estudios teológicos,

5. G. Tovar de Teresa, «Las bibliotecas mexicanas de la primera mitad del siglo XVI», en su Ciudad de México y la utopia en el siglo XVI, México, DF, 1987, p. 65-70.

6. Para una relación bastante completa de las bibliotecas privadas conocidas para América hispana en la época colonial, véase A. Millares Carlo, «Bibliotecas y difusión del libro en Hispanoamérica colonial: intento bibliográfico», Boletín Histórico/Fundación John Boulton (Caracas), no. 22, enero 1970, p. 25-72, que contiene un registro de 188 fichas bibliográficas. Respecto a la mitad del siglo XVII, época en la cual se ubica la colección del doctor Ávila, Millares Carlo señala de modo especial la biblioteca perteneciente a Melchor Pérez de Soto en Ciudad de México, la cual comprendía 1.592 volúmenes, de acuerdo con el inventario levantado en 1655 por el tribunal de la Inquisición.

7. I. A. Leonard, Books of the Brave; being an account of books and of men in the Spanish conquest 
manuales litúrgicos y hagiografías llenaron las necesidades educativas y espirituales de las comunidades eclesiásticas, y daban respuesta a las más profundas interrogantes de los fieles cristianos. El restante 30 por ciento de los libros consistía en poesía, drama y ficción (novelas caballerescas, pastorales, picarescas y de corte), así como en trabajos académicos más serios. Entre estos estuvieron estudios de leyes, historia, política, lingüística, humanidades clásicas y medicina.

Siendo imposible proveer descripciones estadísticas definidas acerca de esas colecciones, parece más razonable enfatizar que los colonizadores españoles disfrutaron, mediante el comercio del libro, de una comunicación directa con los círculos intelectuales de Europa. Glosas modernas de la legislación romana, cruciales debates eclesiásticos, ediciones eruditas del Renacimiento, géneros literarios populares y los últimos avances tecnológicos esparcidos al otro lado del Atlántico circularon con extraordinaria rapidez. Sin hacer caso a la legislación dictada por la monarquía de los Habsburgo, los habitantes de los dominios de ultramar se las arreglaron para leer e inclusive reproducir clandestinamente ciertas publicaciones censuradas: las Sagradas Escrituras en varias lenguas vernáculas, algunos de los trabajos de Erasmo, Constantino Ponce de la Fuente, Luis de Granada, Tommaso de Vio, Juan de Ávila y Denis Rickel, que habían sido prohibidos por supuesta «heterodoxia» por las autoridades eclesiásticas reaccionarias ${ }^{8}$.

Durante los tempranos siglos que discutimos en esta parte del trabajo, la mayoría de los libros registrados en las colecciones hispanoamericanas vinieron del Viejo Mundo. Aparte los centros de publicación españoles más importantes, como Salamanca, Alcalá de Henares, Medina del Campo, Madrid, Toledo y Zaragoza, los libros también se originaron usualmente en Amberes, Lyon, Venecia o Colonia. Aunque no hay confirmación absoluta, quizás el 80 o 85 por ciento de los materiales identificados en las bibliotecas indianas fueron importados de Europa; una menor proporción fueron impresos en Ciudad de México o Lima?

and settlement of the sixteenth-century New World; with a new introduction by Rolena Adorno, Berkeley, CA, 1992, p. 105.

8. Cf. J. Torre Revello, El libro, la imprenta y el periodismo en América durante la dominación española, Buenos Aires, 1940, p. 132-133.

9. Debe ponerse de manifiesto que a lo largo de los siglos XVI y XVII solo cuatro ciudades en la América española gozaron del permiso oficial para establecer un taller tipográfico: México (a partir de 1539), Lima (1584), Puebla de los Ángeles (1640) y Guatemala (1660). La actividad de todos estos centros editoriales ha sido estudiada por José Toribio Medina en cuatro obras clásicas (todas impresas en Santiago de Chile): La imprenta en Lima, 4 vols. (1904-07), La imprenta en México, 8 vols. (1907-12), La imprenta en la Puebla de los Ángeles (1908) y La imprenta en Guatemala (1910). 
¿Qué se puede comentar sobre los vacíos observables en aquellos registros bibliográficos? Ante todo, hay una significativa escasez de crónicas y estudios propios del continente americano: sus civilizaciones precolombinas, sus idiomas, sus costumbres, sus recursos naturales, su condición social bajo el dominio español. Tal deficiencia no se explica simplemente por el predominio de libros europeos importados o la actividad restringida de las imprentas locales, sino principalmente por el concepto fundamental que rigió la adquisición y el coleccionismo de libros en la época. Los materiales impresos fueron utilizados mayormente para mantener contacto con la cultura e ideología europeas, no para acumular más conocimiento sobre una realidad que los colonizadores conocían bien y confrontaban en su vida cotidiana ${ }^{10}$. Comunidades religiosas e individuos particulares, por lo tanto, hicieron grandes esfuerzos para formar ricas y actualizadas colecciones de textos importados directamente de metrópolis distantes.

En otras palabras, los libros fueron percibidos esencialmente como un instrumento para asimilar y armonizar con las tendencias contemporáneas en tecnología, cultura, política y moral europeas. Hasta bien entrado el siglo XVIII los trabajos impresos no fueron tanto un medio de articulación de los intelectuales y burócratas locales con la realidad inmediata, sino más bien vehículos que los mantuvieron conectados con España y el resto de Europa. Un estudio más profundo de esta característica fundamental, me parece, sería un deseable objetivo para cualquier acercamiento sociológico a los hábitos de lectura en la América española colonial.

\section{Censura y Circulación de los materiales impresos}

A comienzos del período colonial en la América española, unos setenta años o menos después de la invención de los tipos movibles por Gutenberg, los libros aún mantenían su reputación como fuentes de conocimiento infalibles y testimonios de la verdad histórica. De este modo, casi todos los tipos de textos, inclusive relatos fantásticos como las novelas de caballerías, podían causar una firme impresión en la mentalidad de los lectores.

El tribunal del Santo Oficio de la Inquisición, activo en Lima, Ciudad de México y Cartagena de Indias desde 1570 en adelante, tuvo a su cargo la tarea de controlar las importaciones de materiales impresos en América. Además, los inquisidores fueron usualmente llamados para juzgar la aceptabilidad

10. Cf. T. J. Dadson, «Libros y lecturas sobre el Nuevo Mundo en la España del Siglo de Oro», Histórica (Lima), vol. 18, 1994, p. 10-12. 
de los manuscritos a ser publicados en el continente americano. La censura inquisitorial no se aplicaba solamente a los textos considerados heréticos y listados en las sucesivas ediciones del Index librorum prohibitorum (1551, 1559,1583 , etc.). Se suponía que la Inquisición debía también controlar y rechazar otros tipos de libros prohibidos en el Nuevo Mundo por las autoridades metropolitanas, como relatos puramente literarios, textos vinculados a la «leyenda negra» antiespañola y obras políticas que se oponían al regalismo y otras aspiraciones fundamentales de la monarquía castellana.

A pesar de esas severas regulaciones, bastantes evidencias revelan que muchos de los libros que fueron oficialmente prohibidos en realidad sí circularon en la América hispana. Los inventarios de las bibliotecas particulares registran varios tipos de narrativa ficcional: romances caballerescos, novelas picarescas y cuentos pastoriles, así como las famosas comedias o dramas populares. Siguiendo la perspicaz advertencia de Torre Revello, se debe considerar que los agentes de la Inquisición fueron especialmente estrictos en controlar la introducción de todo material «herético», desviado de la ortodoxia católica, pero permanecieron relativamente tolerantes con otros, incluyendo textos políticos y literarios tachados como "perniciosos» por la Corona ${ }^{11}$.

Antes del establecimiento de la imprenta y del florecimiento del comercio de libros, todos los materiales impresos tenían que ser transportados personalmente por los interesados $\mathrm{u}$ ordenados directamente desde la Península. Ya hemos dicho que durante los primeros decenios (y aun siglos) de la colonización en América, la mayor parte de los libros registrados en los protocolos notariales provenían del Viejo Mundo. Más adelante, las imprentas se multiplicaron a lo largo de la América española, especialmente durante la era de los Borbones, y se calcula que todo el período colonial vio un estimado de 17.000 títulos publicados en las Indias ${ }^{12}$.

A partir de los años 1930 y 1940 se acumularon nuevas evidencias documentales de gran importancia, procedentes de los registros de embarque, comprobantes de ventas, procesos inquisitoriales y otras fuentes en las cuales se contenían inventarios de libros y bibliotecas privadas, que arrojaron definitivamente nueva luz sobre la circulación de libros en las colonias. En particular dos investigadores, el argentino José Torre Revello (1893-1964) y el norteamericano Irving Albert Leonard (1896-1996), publicaron durante

11.J. Torre Revello, op. cit., p. 47.

12.T. Hampe Martínez, «The diffusion of books and ideas in colonial Peru: a study of private libraries in the sixteenth and seventeenth centuries», Hispanic American Historical Review (Durham, NC, 1993), vol. 73, p. 221-222. Véase también la concisa aproximación de J. G. Johnson (ed.), The book in the Americas. The role of books and printing in the development of culture and society in colonial Latin America, Providence, RI, 1988, p. 67 y ss. 
esos años una serie de libros y artículos en revistas académicas, revelando la existencia de un activo comercio trasatlántico de libros desde Europa hacia el Nuevo Mundo.

En virtud de esta acumulación de noticias históricas, se hizo posible revisar cuestiones antiguas concernientes al libro y al desarrollo de la cultura en la sociedad colonial, abriendo nuevos campos de investigación. El trabajo de esta generación de estudiosos estableció un núcleo de preocupaciones y de metodologías básicas que aún ocupa hoy a la mayoría de los investigadores dedicados a la historia del libro en América Latina.

Un examen del contexto político y social de las publicaciones coloniales hecho a contraluz de la cultura erudita en la Nueva España en los siglos XVI y XVII ha llevado a Magdalena Chocano Mena, investigadora de la Universidad de Barcelona, a observar que la imprenta no se desarrolló como un agente de cambio durante este período. Más que generar condiciones para cuestionar a la autoridad establecida, como había ocurrido en el caso de la Europa de la Reformación, la imprenta sirvió para consolidar el status quo en México. Examinando el contexto en que se desarrolló la vida académica en este virreinato, Chocano Mena destaca el carácter restringido que tuvo la cultura impresa, tomando en cuenta que las principales formas de circular ideas y noticias eran la comunicación y el recurso a las copias manuscritas. Y esto le lleva a cuestionar declaraciones sobre una pretendida «revolución de la imprenta» en esta parte de América, al menos durante los primeros dos siglos de gobierno español ${ }^{13}$.

\section{INVESTIGACIONES RECIENTES:}

\section{CONTINUIDADES Y ALGUNAS NUEVAS DIRECCIONES}

Según advierte Hortensia Calvo, en un reciente y documentado estudio bibliográfico (2003), durante las últimas tres o cuatro décadas la mayor parte de la erudición sobre el libro occidental en los inicios de la América española se ha mantenido en gran parte dentro de los contornos temáticos y metodológicos establecidos por los reconocidos fundadores de la disciplina, que ya hemos mencionado ${ }^{14}$. Sin embargo, como veremos, recientes innovaciones teóricas en los estudios sobre el período colonial han generado algunas críticas sobre los métodos y asuntos tradicionales de los historiadores del libro, a la vez que nuevos rumbos de investigación aspiran a tomar en

13. M. Chocano Mena, op. cit., p. 89-90.

14. H. Calvo, "The politics of print: the historiography of the book in early Spanish America", Book History (University Park, PA), vol. 6, 2003, p. 284. 
cuenta las complejas políticas y realidades de intercambio simbólico que sucedieron tras el contacto europeo-americano.

Para una bibliografía general de los materiales impresos en la región, incluyendo una discusión sobre las imprentas locales, el aumento de los periódicos en el siglo XVIII y la circulación de libros importados, la obra de José Torre Revello, El libro, la imprenta y el periodismo en América durante la dominación española (1940), es todavía una fuente autorizada, mientras que la observación panorámica de Agustín Millares Carlo sobre la historia del libro en Occidente (1971) incluye importantes aportes sobre el establecimiento y desarrollo de la imprenta, así como sobre la historia de las bibliotecas en América Latina ${ }^{15}$. Aparte de estas historias generales, hay algunos estudios complementarios que son dignos de mencionar. Luis Aznar (1940) examina los orígenes y el contexto ideológico de las compilaciones bibliográficas realizadas sobre trabajos acerca de España y la América española; Millares Carlo (1970) investiga el desarrollo de las bibliotecas privadas e institucionales durante el período colonial; y Stephen C. Moler (1978) provee una útil visión general del contexto legal y comercial de las publicaciones hechas en los dominios españoles hasta la Independencia ${ }^{16}$.

Aportaciones más recientes sobre asuntos concernientes a la importación, producción y circulación de materiales impresos para los siglos correspondientes a la Casa de Austria se encuentran, por ejemplo, en un artículo de la recordada investigadora Carmen Castañeda, «Libros en la Nueva Espańa en el siglo XVI» (en La cultura del libro en la Edad Moderna: Andalucía y América, 2001), y en los estudios de Teodoro Hampe Martínez, "The diffusion of books and ideas in colonial Peru» (Hispanic American Historical Review, vol. 73, 1993) y Pedro Guibovich Pérez, «The printing press in colonial Peru: production process and literary categories in Lima» (Colonial Latin American Review, vol. 10, 2001).

Según advierte el trabajo ya citado de Hortensia Calvo, las aproximaciones a inventarios de bibliotecas particulares - con toda la complejidad que el manejo de esta documentación supone- han sido particularmente

15. A. Millares Carlo, Introducción a la historia del libro y de las bibliotecas, México, DF, 1971.

16. Véase L. Aznar, «Precursores de la bibliografía histórica americanista», Humanidades (La Plata), vol. 28, 1940, p. 263-315; Millares Carlo, «Bibliotecas y difusión del libro en Hispanoamérica colonial: intento bibliográfico» [nota 7]; S. C. Mohler, "Publishing in colonial Spanish America», Inter-American Review of Bibliography (Washington, DC), vol. 28, 1978, p. 259-273. 
numerosas para el virreinato del Perú en años recientes ${ }^{17}$. En un campo de estudio caracterizado por la publicación de trabajos aislados o personales, Hampe Martínez y el profesor español Carlos Alberto González Sánchez, de la Universidad de Sevilla, se destacan entre quienes han desarrollado esta propuesta sistemáticamente, examinando catálogos de libros de diversa procedencia para profundizar en los hábitos de lectura y los esquemas de conocimiento sobre un período extendido de tiempo y a través de un espectro social bastante variado. El primero de los nombrados, en su libro Bibliotecas privadas en el mundo colonial (1996), analiza por ejemplo el contenido de colecciones librescas que pertenecieron a abogados, ministros de las audiencias, obispos, funcionarios de la tesorería real y de la Inquisición, un virrey, un cura doctrinero, un conquistador y hasta un curaca o jefe comunal andino ${ }^{18}$.

Un complemento notable al enfoque sobre inventarios de bibliotecas y la circulación de libros importados en el Perú se halla en el artículo de Guibovich Pérez, arriba citado, que contiene una propuesta estadística y un análisis ponderado de la producción de libros y folletos en Lima hasta finales del siglo XVII ${ }^{19}$. De este modo se ratifican algunas nociones ya conocidas sobre las orientaciones temáticas y el contexto social, político e intelectual en que se movieron las elites letradas durante ese período temprano.

En cuanto se refiere al virreinato de Nueva España, recogemos la particular atención que merecen tres series editoriales dedicadas al estudio de la historia del libro y de la cultura impresa, con particular incidencia en la época colonial. En el Colegio de México, desde de los años ochenta del siglo pasado, el Seminario de Historia de la Educación ha producido varias publicaciones sobre la historia social de la lectura y la educación en México virreinal. Complementariamente, la Dirección General de Publicaciones y Fomento Editorial de la Universidad Nacional Autónoma de México viene publicando desde 1987 la colección titulada Biblioteca del Editor, que incluye varias publicaciones dedicadas en todo o en parte a materias del libro colonial. Otro proyecto editorial fue iniciado en 1986 por la Dirección

17. H. Calvo, op. cit., p. 286.

18. Cf. T. Hampe Martínez, Bibliotecas privadas en el mundo colonial: la difusión de libros e ideas en el virreinato del Perú (siglos XVI-XVII), Frankfurt am Main \& Madrid, 1996; C. A. González Sánchez, Los mundos del libro: medios de difusión de la cultura occidental en las Indias de los siglos XVI y XVII, Sevilla, 1999.

19. P. Guibovich Pérez, «The printing press in colonial Peru: production process and literary categories in Lima, 1584-1699", Colonial Latin American Review (New York), vol. 10, 2001, p. 173-182. Este investigador propone una clasificación de los impresos limeños en cuatro categorías: (1) obras eclesiásticas, (2) documentos de la autoridad civil, (3) textos universitarios y del ámbito intelectual, (4) ciencias aplicadas. 
General de Bibliotecas de la Secretaría de Educación Pública de México, comprendiendo una sección sobre bibliotecas coloniales como parte de una ambiciosa Historia de las bibliotecas en México, formada por cinco volúmenes, cuyo objetivo es presentar la historia general de las bibliotecas en México hasta la actualidad ${ }^{20}$.

Como todo conglomerado humano, la naciente sociedad colonial del Nuevo Mundo sintió la necesidad imperiosa de comunicarse, ya sea para repartir instrucciones, emitir protestas o difundir noticias. Es obvio, sin embargo, que durante las primeras décadas del establecimiento colonial en los Andes, siendo escasos los textos impresos y ninguna la posibilidad de imprimir en el medio local, la comunicación fue básicamente oral. En el seno de conjuntos urbanos pequeños, donde prácticamente todos los habitantes se conocían, las novedades se transmitían de boca en boca (con todas las características y limitaciones que este hecho supone).

\section{PRIMERA ETAPA: RELACIONES Y NOTICIARIOS}

Por cierto que las fabulosas noticias del grandor y riqueza del Imperio de los incas, junto con los detalles de la captura de Atahualpa por las huestes de Pizarro, merecieron un eco inmediato en Europa (y en diversos idiomas vernáculos), gracias a las relaciones de los más tempranos cronistas. Aquí, empero, nos interesa el fenómeno del "periodismo" generado en la propia región andina, el cual no será factible sino hasta finales del siglo XVI, como resultado de la puesta en marcha de las prensas de Antonio Ricardo, en Lima. De hecho, María Mendoza Michilot ha dedicado un estudio monográfico a las relaciones y los noticiarios, «hojas volantes no periódicas que son reconocidas como las manifestaciones primigenias del periodismo en el Perú» ${ }^{21}$.

Se asume que en 1594 apareció la primera relación en Lima, refiriendo las incidencias de la captura del pirata inglés John Hawkins por la escuadra virreinal. En realidad, era la copia de un impreso semejante que se había

20. Véase R. M. Fernández de Zamora, «La historia de las bibliotecas en México, un tema olvidado", 60th IFLA General Conference Proceedings, La Habana, 21-27 de agosto 1994 (http://www.ifla.org/IV/ifla60/60-ferr.htm).

21. M. Mendoza Michilot, Inicios del periodismo en el Perú; relaciones y noticiarios, Lima, 1997, p. 24. 
divulgado primero en la Península ${ }^{22}$. Y es que las relaciones y los noticiarios informaban generalmente sobre acontecimientos importantes para la corte espańola, brindando novedades acerca de nacimientos, matrimonios o decesos de miembros de la familia real, o grandes sucesos de la vida política, militar y religiosa. Siendo tan pequeño y conocido el ambiente donde habitaban los colonizadores del Nuevo Mundo, ¿qué necesidad habría de llevar las noticias cotidianas a la imprenta?

La aparición de aquellos medios informativos dependía, pues, de la llegada de los «navíos de aviso» por el Mar del Sur. Esto determinaba no sólo una sensible (aunque inevitable) tardanza en la difusión de las noticias -se podía dar por satisfecho cualquiera que captase las novedades europeas con medio año de atraso-, sino también una marcada influencia de los estándares y normativas fijadas en la metrópoli. Las materias que tratan las relaciones y noticiarios son diversas: van desde las fiestas por las canonizaciones de San Ignacio de Loyola y Santa Teresa de Ávila hasta la entrada de los corsarios holandeses en la bahía de Cádiz, pasando por la rendición de la ciudad flamenca de Breda y los sucesos de la revuelta catalana de 1640 .

Las relaciones exponen un hecho en particular y se asemejan, por su tamaño y extensión, a meras hojas arrancadas de un libro. En cambio, los noticiarios (identificables con primitivas "gacetas») poseen una forma más elaborada, contienen varias noticias juntas y suelen repetir secciones informativas de interés general. Estas publicaciones se editaron durante el siglo XVII en los talleres de imprenta limeños, por encargo de las autoridades civiles y eclesiásticas, generalmente en cortísimas tiradas, debido a la escasez de gente capacitada para leer. Tuvieron por lo general una breve duración y su producción fue a menudo irregular.

En definitiva, según concluye el estudio de Mendoza Michilot, las relaciones y los noticiarios fueron instrumentos sujetos a la censura oficial, influidos directamente por los órganos periodísticos de España, tanto en la forma como en el fondo. Su mecánica de funcionamiento implicaba una audiencia bastante restringida - los criollos, mestizos e indígenas letradosy una actitud esencialmente pasiva de los receptores. En palabras de dicha investigadora ${ }^{23}$, se practicó a través de dichos medios una «relación enunciador-destinatario de tipo jerárquico, unidireccional, normativo y hasta vertical», tendiente a garantizar la reproducción en el mundo colonial de modelos y reglas de la cultura peninsular.

22. C. A. Romero, Los origenes del periodismo en el Perú; de la relación al diario (15941790), Lima, 1940, p. 10-11.

23. M. Mendoza Michilot, op. cit., p. 19. 
Salvando el caso excepcional del Diario de Lima, que inició en 1629 Juan Antonio Suardo y fue continuado por Josephe de Mugaburu, con un relato pormenorizado de los sucesos que ocurrían día a día en la capital del virreinato, pero que permaneció inédito en su época ${ }^{24}$, habrá que esperar hasta el siglo XVIII para la aparición de órganos de prensa de carácter periódico. La vanguardia en este género corresponde a la Gaceta de Lima, un boletín de noticias que editaban los propios encargados del mando en el virreinato del Perú. No pareciera que tuvo demasiada circulación este periódico, pues sólo han quedado hasta hoy ciertos números sueltos de los años 1715, 1743-44, 1756-65, 1776, 1793-94 y $1798^{25}$.

Lo importante de la Gaceta de Lima es que su salida obedeció a una rutina o periodicidad, generalmente mensual, creando así una expectativa ordenada entre el público lector de la época. Este periódico oficialista (de dos a cuatro hojas de extensión) solía reproducir informaciones de órganos de prensa de Madrid, dando cuenta de los acontecimientos sociales y políticos más notables en la vida de las cortes europeas. ¿¿Hasta qué punto llamaba la Gaceta limeña -impresa en los talleres tipográficos de la calle San Ildefonso, la calle Coca y los Huérfanos- la atención de los pobladores coloniales? En verdad, no parece que fuera un objeto muy codiciado, a estar por las frecuentes variaciones en su formato y las repetidas lagunas en su edición.

Durante los últimos años, la diligente labor investigadora de José Durand permitió reconstruir con mayor certeza la existencia y trasfondo de la Gaceta de Lima, a la cual suele considerarse el periódico «regular» más antiguo de la América del Sur. Tal como ha llegado hasta nuestros días, la Gaceta «constituye un documento irreemplazable para la historia colonial del siglo XVIII», decía el citado investigador ${ }^{26}$. El propio Durand tuvo ocasión de formar una valiosa colección de números de este periódico, los cuales editó con primor y hoy están a disposición de los estudiosos en la Hesburgh Library de la Universidad de Notre Dame ${ }^{27}$.

24. Cf. las respectivas versiones impresas de J. A. Suardo, Diario de Lima (1629-1634), ed. de Rubén Vargas Ugarte, S.J., Lima, 1935, y J. y F. de Mugaburu, Diario de Lima (16401694); crónica de la época colonial, ed. de Carlos A. Romero, Lima, 1935.

25. Cf. E. D. Temple, La «Gaceta de Lima» del siglo XVIII. Facsimiles de seis ejemplares raros de este periódico, Lima, 1965; J. Durand (ed.), "Gaceta de Lima» (1756-62, 1762-65, 179394). Recopilación, prólogo y apéndices de [...], Lima, 1982-83, 3 vols.

26. J. Durand (ed.), Prólogo a "Gaceta de Lima», vol. I (De Superunda a Amat), Lima, 1982, p. xiii.

27.T. Hampe Martínez, «José Durand, bibliófilo: su colección de libros y papeles en la 
A base de un análisis de contenidos, Tamar Herzog ha sugerido que la Gaceta de Lima no debe ser vista como un periódico, sino como la crónica intencionada de "una ciudad señorial que pasa su tiempo y gasta su energía en actividades ceremoniales, en donde la paz y la armonía prevalecen» ${ }^{28}$. Pero en los tramos finales de su salida, este órgano se hallaba virtualmente divorciado del acontecer local de la ciudad donde se imprimía, y también ignoraba las demás provincias del virreinato peruano. En ese tiempo, que coincide con los sangrientos acontecimientos de la Francia revolucionaria, la Gaceta asumirá con firmeza la posición de los monarquistas, críticos de la «barbarie» parisina.

Hay que tener en cuenta que, junto a los obstáculos de una imprenta local restringida por controles oficiales y problemas tipográficos de variada índole (como los altos costos de la maquinaria importada y la crónica escasez de papel), la producción de noticiarios y gacetas en Hispanoamérica colonial resultó entorpecida por la existencia de pequeños grupos de suscriptores. Lo cierto es que la publicación de papeles periódicos, así como de libros, era una empresa costosa y comercialmente riesgosa.

\section{LOS PERIÓDICOS BAJO EL INFLUJO DE LA ILUSTRACIÓN}

El primer papel diario de la América meridional salió a la circulación en la capital peruana, el 1 de octubre de 1790, con el título de Diario de Lima (curioso, erudito, económico y comercial). Su editor fue el activo hombre de letras español Francisco Antonio Cabello y Mesa, quien había llegado pocos años atrás de la Península y se cubría bajo el seudónimo de Jaime Bausate y Mesa. Gracias a la minuciosa investigación realizada por Mónica P. Martini, hoy conocemos en detalle las actividades periodísticas de este personaje en el viejo y el nuevo continente ${ }^{29}$. Se sabe que sacó su periódico en Lima contando con el apoyo del virrey Gil de Taboada, y luego de cerrada la empresa se dirigió a Buenos Aires, donde inició con similares rasgos la publicación del Telégrafo del Río de la Plata ${ }^{30}$.

El Diario de Lima, que se elaboraba en la Imprenta de los Huérfanos, daba noticias de sucesos acaecidos en el Perú y en la madre patria. También

Universidad de Notre Dame», Revista de Indias (Madrid), vol. 57, 1997, p. 541-562.

28. T. Herzog, «La Gaceta de Lima (1756-1761): la reestructuración de la realidad y sus funciones», Histórica (Lima), vol. 16, 1992, p. 46.

29. M. P. Martini, Francisco Antonio Cabello y Mesa, un publicista ilustrado de dos mundos (1786-1824), Buenos Aires, 1998.

30. Cf. J. Torre Revello, op. cit., p. 187 y ss., y «Datos para la biografía del primer periodista porteño, Francisco Cabello y Mesa», Universidad (Santa Fe), vol. 21, 1949, p. 101-122. 
incluyó algunas descripciones geográficas, ensayos históricos y disertaciones científicas, que se orientaban al público más ilustrado. El editor recurrió al servicio de los propios vecinos para que brindaran noticias, las cuales aparecían como pequeños avisos sueltos: tuvo así un carácter local y un sabor auténticamente limeño.

En su época de mayor bonanza, la publicación dirigida por Cabello y Mesa se distribuía más allá de los confines del territorio peruano, pues consta que poseía lectores en toda la extensión que abarca desde Cajamarca hasta Chuquisaca y Potosí. Pero fue tal vez por descuidar el material informativo del día que, progresivamente, decayó su nivel de interés y su circulación. Con problemas económicos a cuestas, el Diario de Lima no pudo enfrentar la competencia de los otros órganos de información que aparecieron en los últimos tramos del siglo XVIII, tuvo que reducir su formato y terminó por cerrar el 26 de septiembre de $1793^{31}$.

Por el mismo tiempo se publicaba en Lima, desde enero de 1791 (dos veces a la semana, los jueves y domingos), el Mercurio Peruano, de historia, literatura y noticias públicas, famoso órgano de la Sociedad Académica de Amantes del País, que constituyó la máxima creación en materia periodística en los tiempos de la Colonia. Su fama alcanzó hasta las cortes regias europeas, donde ministros e intelectuales se ocupaban en leer las eruditas colaboraciones que en el Mercurio publicaban Hipólito Unanue, José Baquíjano y Carrillo, Toribio Rodríguez de Mendoza, Jacinto Calero y Moreira, Vicente Morales Duárez y otros finos ingenios de la época. Para evadir las censuras del gobierno virreinal, estos ilustrados criollos utilizaban seudónimos, generalmente de inspiración clasicista ${ }^{32}$.

Según está claramente asentado en las notas editoriales, el Mercurio Peruano salía a la luz para "hacer más conocido el país que habitamos» y combatir los paralogismos o razonamientos falsos que habían echado a correr autores extranjeros. En las hojas de este medio se combinaban reflexiones políticas y evocaciones históricas con tratados sobre la geografía, economía, costumbres y recursos naturales del Perú. La mejor investigación sobre la trayectoria del Mercurio se debe al catedrático francés Jean-Pierre Clément: su estudio crítico discute aspectos materiales de la creación, edición y recepción del periódico y trata ampliamente sobre los aspectos ideológicos y las fuentes que influenciaron a los redactores ${ }^{33}$.

31. Véase el breve resumen que ofrece R. Porras Barrenechea, El periodismo en el Perú; 130 años de periódicos (1791-1921), Lima, 1970, p. 8-11 y 92-94.

32. J. P. Clément, Índices del "Mercurio Peruano", 1790-1795; prólogo de Estuardo Núñez, Lima, 1979, p. 10

33. J. P. Clément, El «Mercurio Peruano», 1790-1795, vol. 1: Estudio, Frankfurt am Main 
A pesar del escaso número de ejemplares que publicaba (entre 400 y 575 , dependiendo de las circunstancias), el Mercurio Peruano gozó de amplia repercusión entre la población blanca de descendencia española que habitaba en Lima y en las capitales provinciales del virreinato. Clément muestra en un cuadro estadístico que la geografía, la medicina y la historia fueron los temas comunes más discutidos, cubriendo en conjunto hasta el 50 por ciento de la «superficie» impresa total del periódico ${ }^{34}$. Esta preferencia en contenidos pone en evidencia el interés de los editores por destacar la realidad física y humana del Perú, su patria, tanto en el pasado como en el presente ${ }^{35}$.

Por otra parte, aunque inspirada en los principios renovadores de la Ilustración francesa, es obvio que la Sociedad Académica de Amantes del País representaba los intereses de la aristocracia criolla limeña de fines del siglo XVIII. Si bien los miembros de la Sociedad tendieron a ser «burgueses modernos» (según Clément), aquella corporación incluía de hecho a altos burócratas, nobles, militares y clérigos junto con comerciantes, banqueros, terratenientes, empresarios mineros, fabricantes, etc. En defensa de su privilegiada posición, los criollos ricos crearon argumentos para controlar a los indios y castas mestizas - que constituían la mayoría de la población-, y así cooperaron con la monarquía española.

$\mathrm{Al}$ respecto de esto último, es interesante observar la actitud de los criollos hacia la Revolución Francesa y su agenda política radical, que coincidió plenamente con la publicación del Mercurio. En varios artículos y noticias reproducidas del extranjero, el periódico declaró su oposición a los excesos cometidos en la Revolución, considerándolos como actos sacrílegos y antihumanos $^{36}$. Dada esta alianza con los intereses gubernativos españoles, parece difícil aceptar la conclusión de Clément de que el periódico limeño desapareció principalmente a causa de la voluntad negativa de las autoridades virreinales ${ }^{37}$.

Otra explicación, y quizás más apropiada, puede encontrarse en la crisis financiera y el alza de precios que afectaban al mercado peruano tras la introducción del régimen de comercio libre: estos factores debieron de influir directamente en el fin de la empresa periodística. Al cabo de doce

\& Madrid, 1997.

34. Ibidem, p. 98.

35. Cf. J. I. López Soria, Ideología económica del "Mercurio Peruano», Lima, 1972; J. Mariátegui, El «Mercurio Peruano» y la medicina, Lima, 1994.

36.T. Hampe Martínez, «La Revolución Francesa vista por el Mercurio Peruano: cambio político vs. reformismo criollo», Boletín del Instituto Riva-Agüero (Lima), vol. 15, 1988, p. 167-173.

37. J. P. Clément, op. cit., vol. 1, p. 263. 
volúmenes entregados, que representaban más de 400 números, el Mercurio Peruano dejó de circular a comienzos de $1795^{38}$.

También de la mencionada Imprenta de los Huérfanos, salió a partir de junio de 1791 un interesante órgano de noticias y comentarios sobre la realidad peruana: el Semanario Crítico, dirigido por el sacerdote franciscano Juan Antonio de Olavarrieta ${ }^{39}$. Arrancó este periódico con un prospecto, en el cual prometía constituirse en instrumento de «reflexiones críticas sobre la educación, costumbres públicas, poesía teatral, y otras diferentes materias». Sólo alcanzaron a circular 16 entregas del hebdomadario, hasta septiembre de 1791, cuando Olavarrieta decidió suspender su actividad por la nociva hostilidad y pugna con los otros órganos limeños que hemos reseñado.

Se caracterizó el Semanario Crítico por enfrentarse al Mercurio Peruano, poniendo frecuentemente en tela de juicio los trabajos de investigación que los «amantes del país» presentaban y acusando a dichos redactores de plagiarios. En opinión de Ella Dunbar Temple, el órgano dirigido por Olavarrieta trasunta un conjunto de ideas reaccionarias, encarnando «el más ańejo sentir conservador, ajeno y opuesto a las novedades doctrinarias». Por el modo de enfocar los temas y por su estilo resulta -según dicha autora- un periódico monótono y presuntuoso, de columnas somnolientas y apocadas, carentes de toda tipicidad local ${ }^{40}$. Un punto de vista distinto ha sido manifestado, empero, en algunos trabajos de la última década: Zamalloa Armejo, por ejemplo, anota que Juan Antonio de Olavarrieta fue un auténtico liberal, amigo de las masas y seguidor de la Ilustración ${ }^{41}$.

\section{PASQUINES Y PRENSA DE LA EMANCIPACIÓN}

Además de una serie de relaciones, noticiarios, gacetas y periódicos que aparecieron de manera dispersa, fue usual en el tiempo de la Colonia la circulación de pasquines u hojas volantes, que se imprimían clandestinamente y servían para canalizar las inquietudes y quejas de algunos grupos sociales inconformes. La utilización de los pasquines (que se colocaban, anónimamente, en las puertas de las iglesias o en los muros de las calles) se

38. Cf. J. T. Medina, La imprenta en Lima (1584-1824), vol. III, Santiago de Chile, 1905, p. $220-222$.

39. R. Forns Broggi, "Relectura del Semanario Critico de Juan Antonio de Olavarrieta (Lima, 1791)», Lexis (Lima), vol. 15, 1991, p. 74-75.

40.E. D. Temple, «Periodismo peruano del siglo XVIII: el Semanario Crítico», Mercurio Peruano (Lima), vol. 25, 1943, p. 454.

41. Véase R. Zamalloa Armejo, "La polémica entre el Mercurio Peruano y el Semanario Crítico (1791)», Histórica (Lima), vol. 17, 1993, p. 109-118. 
acentuó durante la segunda mitad del siglo XVIII, al agudizarse el descontento por las medidas de presión fiscal que imponía el régimen de los Borbones. Más aún, se puede hablar de una "guerra de los pasquines", ya que el mismo instrumento de propaganda fue empleado por el bando contrario -el afín a la Corona- para repeler las críticas y justificar el orden establecido.

Momento culminante de dicha efervescencia política fue el año 1780, en que estalló la gran rebelión andina del cacique Túpac Amaru en el Cuzco. Pocos meses antes, ese mismo año, había surgido en Arequipa un movimiento contrario al régimen español. Se caracterizó esta revuelta por los pasquines que llamaban a desobedecer al corregidor de la provincia ${ }^{42}$. Partiendo de Arequipa, la rebelión de los pasquines se extendió por diversos lugares de la serranía andina, y aunque los responsables de dichos manifiestos nunca daban abiertamente la cara, algunos sospechosos fueron perseguidos y aun ejecutados (como es el caso de Lorenzo Farfán de los Godos). A través de este canal de difusión los alzados cuestionaban el abuso de los malos funcionarios, rechazaban las medidas impuestas por la Corona, formulaban propuestas de reforma y comparaban inclusive la gestión de la monarquía española con otras extranjeras, lo cual demuestra que ellos estaban relativamente bien informados. El grito de «Viva el rey y muera el mal gobierno!», que se repite en varios de los manifiestos del siglo XVIII, resonará con mayor fuerza durante el período de la Emancipación, y especialmente a partir de las juntas de gobierno que se formaron en Hispanoamérica tras la invasión de las tropas napoleónicas a la Península.

En tal coyuntura, como es sabido, los diputados liberales reunidos en Cádiz emitieron una serie de resoluciones novedosas, incluyendo el decreto de la libertad de impresión de octubre de 1810 y la supresión del Tribunal de la Inquisición, que (según está dicho) ejercía la censura de los impresos. Al amparo de estas permisivas regulaciones, aparecieron en el Perú una serie de periódicos y panfletos. Durante el gobierno del virrey don José Fernando de Abascal (1806-1816) aparecieron hasta catorce periódicos, de desigual importancia. De ellos, El Peruano, por su relativa duración y sus planteamientos político-doctrinarios, es sin duda el más calificado.

El Peruano de 1811-1812 representa el instante de máxima tensión en las relaciones de Abascal con la prensa. Este papel impreso, que podemos denominar precursor, y que terminó siendo censurado y prohibido, estaba cercanamente vinculado con el espíritu y los acontecimientos de las Cortes generales ${ }^{43}$. El Peruano trató temas de afirmación de la personalidad peruana

42. Cf. G. Galdos Rodríguez, La rebelión de los pasquines; un intento emancipador de Arequipa colonial (1780), Arequipa, 1967.

43. Cf. A. Martínez Riaza, "Los orígenes del periodismo doctrinario en Perú: el caso 
y americana. Por ello, aunque no planteara directamente el separatismo de España, puede decirse que ocupó el lugar crítico y propagandístico de las novedades ideológicas, marcando el segundo paso en la historia del periodismo peruano durante el proceso de la Emancipación. Fue de alguna manera un heredero del Mercurio Peruano, ya que colaboraron en él antiguos miembros de la Sociedad de Amantes del País, como Hipólito Unanue.

Curiosamente, El Peruano se debía a la permisión oficial de Abascal y muchos criollos en proceso de sentirse en las filas de los peruanos pensaban que su contenido era cultural. Este bisemanario, que se editaba en las prensas de Guillermo del Río en Lima, comenzó a salir el 6 de septiembre de 1811. Ofrecía noticias sobre la guerra que se libraba en España contra la invasión y usurpación de los franceses y sobre las tareas legislativas que realizaban las Cortes. En las páginas de El Peruano se defendía la soberanía popular y se llegó a censurar e insultar los abusos de algunas autoridades locales, motivo por el cual el virrey Abascal decidió (al cabo de nueve meses) clausurar la publicación, aduciendo que Gaspar Rico y Angulo -su principal redactorhabía propalado «doctrinas tumultuarias, sediciosas y revolucionarias» ${ }^{44}$.

Es un hecho cierto que este medio de comunicación propulsaba la soberanía del pueblo; al menos estaba en consonancia con uno de los principios vitales de la Revolución Francesa. No era ni es necesario juzgarlo con los ojos de nuestro tiempo, y menos exigir que para calificarlo de instrumento doctrinario liberal debería haber cumplido una serie de requisitos. El Peruano apunta su preocupación por la situación económica y trata de aportar ideas que contribuyan a solucionar los problemas más acuciantes. Estamos de acuerdo con Ascensión Martínez Riaza, por lo demás, cuando señala que «de toda la prensa del primer período constitucional, es sin duda este periódico el que con más eficacia y sistematización defiende los intereses criollos» ${ }^{45}$.

En esta época se publicaba la Gaceta de Gobierno de Lima, órgano antirrevolucionario y al servicio de la oficialidad virreinal que, pese a proporcionar información controlada por las autoridades, dejaba filtrar a través de ciertos comentarios la verdadera situación en Espańa y en América. Es importante señalarla aquí porque, en forma paradojal, haciendo uso de las propias ideas de la Ilustración, intentó reprimir y detener la inminente caída del virreinato peruano. La Gaceta de Gobierno publicó los decretos

conflictivo de "El Peruano"», Quinto Centenario (Madrid), no. 3, 1982, p. 117.

44. C. Villanueva, "El Peruano y la libertad de imprenta, 1811-1812», Boletín del Instituto Riva-Agüero (Lima), vol. 8, 1969/71, p. 543-553, trata sobre las intervenciones de la Junta Provincial de Censura contra este periódico.

45. A. Martínez Riaza, op. cit., p. 124. 
de las Cortes generales y extraordinarias, al mismo tiempo que procuraba controlar la opinión pública bajo la dirección del sagaz Abascal ${ }^{46}$.

Desde la llegada y aplicación del decreto de la libertad de imprenta en el país, en abril de 1811, se harán más frecuentes las críticas al gobierno. En este contexto, El Peruano y El Satélite del Peruano cumplirán un eficiente papel de vanguardia, siendo suprimidos muy pronto; aparecerán luego El Cometa, Argos Constitucional, El Peruano Liberaly El Investigador. Todos estos medios procuran contrarrestar la acción de la Gaceta de Gobierno de Lima, lo que da lugar a interesantes publicaciones de corte polémico, encaminadas a crear una conciencia política -separatista o no- entre los súbditos peruanos.

Para enmendar o contrarrestar los efectos de esa corriente de opinión, Abascal propició la edición de El Verdadero Peruano, que comenzó a circular en septiembre de 1812. Fueron sus editores el presbítero Tomás Flores y el doctor José Pezet. El virrey, monárquico duro, tuvo una gran influencia sobre la libertad de imprenta decretada por las Cortes, y hay abundante bibliografía como para asegurar que él interfirió e influyó contra dicha libertad. Abascal decidía qué era publicable y perseguía a aquellos cuyos criterios no le complacían. Por ello mantuvo conflictivas relaciones con instituciones como la Iglesia y la Universidad. Sea como fuere, el retorno de Fernando VII al trono español y la reimplantación de la monarquía absoluta, en 1814 , llevaron consigo el fin de la primavera de libertad que se había gozado en los años que tratamos ${ }^{47}$.

En gran parte, la investigación sobre libros y cultura impresa para el siglo XVIII y la época de la Independencia comparte el mismo enfoque temático y rigor metodológico de los trabajos dedicados a los siglos anteriores. Aunque los registros de transporte marítimo, en una época en la cual decayó la severidad punitiva de la Inquisición, no son tan consistentes como para la era de los Habsburgo, se ha mantenido la frecuentación de los inventarios de bibliotecas privadas para determinar la diseminación de las ideas europeas, como lo demuestra un gran número de ensayos. Otro enfoque común para este período tardocolonial se ha centrado en el establecimiento de la imprenta en ciudades como Santafé de Bogotá, Quito, Buenos Aires, y otras capitales de gobernaciones o virreinatos ${ }^{48}$. Además de ello, está recibiendo una creciente atención la producción de literatura periódica, a cargo de los grupos de criollos ilustrados.

46. Cf. M. L. Rivara de Tuesta, Ideólogos de la Emancipación peruana. 2a ed. Toluca, 1988, p. 6-8 y $20-21$.

47. Véase al respecto el magnífico trabajo de A. Martínez Riaza, La prensa doctrinal en la independencia del Perú, 1811-1824, Madrid, 1985, especialmente las p. 30-41 y 150-152.

48. H. Calvo, op. cit., p. 288. 
En definitiva, hoy está comenzando a ser explorado el rol que desempeñaron las imprentas locales en dar forma al cambio ideológico y político del período de la Independencia. Cualquier consideración sobre el rol de los materiales impresos como elemento neurálgico de la vida intelectual comunitaria, en la dimensión que Benedict Anderson ha planteado, debe tomar en cuenta una serie de factores diversos ${ }^{49}$. Varios trabajos recientes realizan justamente este ejercicio al examinar las formas en las cuales la literatura periódica incentivó nuevas prácticas de lectura y la emergencia de espacios públicos novedosos, como los cafés y los salones literarios. Investigaciones modernas sobre el tema de la Ilustración y la propagación del espíritu racionalista tienden a acentuar que fueron especialmente los aspectos culturales, científicos y económicos del enciclopedismo los que prendieron en el Nuevo Mundo, y no tanto las ideas políticas subversivas de la Revolución Francesa, que tendieron a ser rechazadas por las elites criollas ${ }^{50}$. Se puede decir entonces que el revolucionarismo fue promovido retrospectivamente, como un resultado y no como la causa de los movimientos de independencia.

\section{PERSPECTIVAS: RECONSIDERACIÓN DEL LIBRO Y OTROS ELEMENTOS}

A guisa de síntesis, se puede afirmar que las proposiciones subyacentes a los estudios tradicionales sobre la historia del libro en América hispana, vale decir, la existencia de colonos ibéricos oprimidos por la represión estatal, por un lado, y la celebración del rol civilizador de las benevolentes instituciones españolas en el Nuevo Mundo, por el otro, han sido modificadas por una serie de logros académicos durante los últimos años, incluyendo contribuciones de la semiótica, teorías del discurso postmodernas, nuevos entendimientos sobre la evolución intelectual de las elites urbanas criollas e investigaciones acerca de la resistencia simbólica y real contra el gobierno español en el seno de las sociedades coloniales americanas. Asimismo, los estudiosos del período de la Independencia se muestran de acuerdo en conferir a la naciente prensa doctrinaria una función didáctica, junto con la defensa de una ambigua opinión pública.

Una de las propuestas más críticas y consistentes en contra de los aportes tradicionales de la historiografía del libro proviene de Rolena Adorno, una

49. B. Anderson, Imagined communities: reflections on the origin and spread of nationalism, rev. ed., London, 1991, p. 61-62.

50. Cf. C. Rosas Lauro, Del trono a la guillotina: el impacto de la Revolución Francesa en el Perú 1789-1808, Lima, 2006, p. 100-122. 
erudita hispanista y andinista de la Universidad de Yale, quien ha realizado contribuciones sobre las prácticas simbólicas hechas por y acerca de los amerindios en los inicios de la América española. En su introducción a la última edición del clásico Books of the brave de Irving A. Leonard (1992), Adorno cuestiona explícitamente las opiniones de los tempranos historiadores del libro en lo referente a la influencia de las novelas de caballerías en los escritos sobre la Conquista y en la mentalidad de los conquistadores ${ }^{51}$.

Ya previamente, dicha investigadora había argumentado contra las premisas teóricas y temáticas de la historiografía tradicional, destacando el éxito editorial que obtuvieron en Espańa algunas composiciones acerca del contacto inicial con los amerindios, creadas dentro del género épico: verbigracia, La Araucana de Alonso de Ercilla y las Elegías de varones ilustres de Indias de Juan de Castellanos. Por oposición a éstas, los tratados y crónicas de carácter etnohistórico sobre el mismo tema, realizados por testigos presenciales de la Conquista, permanecieron durante largo tiempo inéditos. Adorno llega a la conclusión de que, más que despertar la imaginación de los conquistadores hacia hazañas nobles -como Leonard había sugerido- las convenciones rígidas de formas de representación épica fueron promovidas por la Corona hacia fines políticos ${ }^{52}$.

Por otro lado, mientras estudios teóricos recientes sobre el estudio de las primeras sociedades hispanoamericanas están generando una reevaluación explícita de esos asuntos tradicionales, algunos aspectos de comunicación alterna -más allá del texto y de la materia impresa- están siendo explorados, como en la excelente compilación de ensayos que Elizabeth Hill Boone y Walter D. Mignolo han producido, Writing without words (1994). De esta manera se han reflejado más complejidades y circunstancias únicas de los manuscritos y la comunicación intercultural durante el período colonial ${ }^{53}$.

En ese mismo sentido, el ya citado Mignolo ha situado las tempranas concepciones del libro a la luz de las filosofías del lenguaje y de la escritura prevalecientes en el Renacimiento europeo, las cuales dieron evidente

51. R. Adorno, "Introduction", en I. A. Leonard, Books of the brave: being an account of books and of men in the Spanish conquest and settlement of the sixteenth-century New World, Berkeley, CA, 1992, p. xix-xxiv.

52.R. Adorno, "Literary production and suppression: reading and writing about Amerindians in colonial Spanish America", Dispositio (Ann Arbor, MI), vol. 11, 1986, p. 5-8, manifiesta que las limitaciones estrictas del género épico permitían controlar mejor la imagen con que se representaban el carácter y los usos de las civilizaciones amerindias: en la composición poética se encasillaba a los sujetos dentro de unos moldes de representación familiares, de manera que había como una previa "ficcionalización" de la realidad.

53. E. H. Boone y W. D. Mignolo (eds.), Writing without words: alternative literacies in Mesoamerica and the Andes, Durham, NC, 1994. 
prioridad a las formas occidentales de registro (papel, libro, instrumentos de escritura) como vehículos para la transmisión del conocimiento y de la memoria colectiva. Así se relegaban, por cierto, las formas típicamente amerindias de registro de la información, que se mantuvieron al uso en un plano subalterno ${ }^{54}$.

Mucho queda por explorar aún, pues, con respecto al impacto que ejercieron las bibliotecas, el comercio de libros y los talleres de imprenta sobre la vida social y cultural de la América española colonial. Como hemos visto, dado el rol restringido de la cultura impresa durante este período, los investigadores están buscando otras posibilidades de información y enfoques alternativos para capturar y ampliar nuestra visión sobre las circunstancias particulares de este fenómeno. Lo interesante se halla en esa ampliación de perspectivas, que no se limita a profundizar en las honduras y múltiples significaciones del material impreso, sino apunta a observar la intersección entre formas de expresiones textuales y no textuales.

Con mayor especificidad, diremos que los estudios enfocados en inventarios de bibliotecas privadas y registros de transporte marítimo deberían ser ampliados por una investigación complementaria en otras fuentes archivísticas y otras facetas del entorno cultural. Entre los documentos suplementarios estarían las listas de propiedades confiscadas por la Inquisición y los inventarios de las tiendas de libros, las bibliotecas académicas y las colecciones de comunidades religiosas, incluyendo el registro sistemático de los materiales e instrumentos que poseían los colegios de la Compañía de Jesús al momento de su expulsión $(1767)^{55}$. También podemos mencionar las ordenanzas y programas de estudios de universidades y colegios; las actas de exámenes, graduaciones y oposiciones a cátedras y curatos; las relaciones de méritos y servicios personales, etc.

Para terminar, las investigaciones del futuro en esta materia también deberían tomar en consideración la literatura producida en las Indias por autores locales y el amplio dominio de la iconografía. Solo de este modo, a través de un trabajo interdisciplinario e intenso, se podrá avanzar por los pedregosos caminos de la espiritualidad y la cultura.

54. Véase las interesantes propuestas sobre memorias coexistentes y espacios alternativos de W. D. Mignolo, «Misunderstanding and colonization: the reconfiguration of memory and space», en Le Nouveau Monde, mondes nouveaux. L'expérience américaine, dir. Serge Gruzinski y Nathan Wachtel, Paris, 1996, p. 290 y ss.

55.V. Oliver Muñoz, «La biblioteca del Colegio Máximo de San Pablo de Lima (15681767): una descripción", Anuario del Archivo y Biblioteca Nacionales de Bolivia (Sucre), vol. 10, 2004, p. 817-828. 